\title{
Joining of Inconel 718 and 316 Stainless Steel using Electron Beam Melting additive manufacturing technology
}

\author{
Alejandro Hinojos ${ }^{1}$, Jorge Mireles ${ }^{*}{ }^{1}$, Ashley Reichardt ${ }^{3}$, Pedro Frigola ${ }^{2}$, Peter Hosemann ${ }^{3}$, Lawrence E. \\ Murr $^{1}$, Ryan B. Wicker ${ }^{1}$ \\ ${ }^{1}$ W.M. Keck Center for 3D Innovation at the University of Texas at El Paso1, El Paso, Texas \\ ${ }^{2}$ RadiaBeam Systems, Santa Monica, CA \\ ${ }^{3}$ Department of Nuclear Engineering at the University of California at Berkeley3
}

*Corresponding author:

500 W. University Ave., E108, El Paso, Texas 79968

Phone: (915) 747-6837, E-mail: jmireles3@utep.edu 


\begin{abstract}
Joining of dissimilar metals using high energy-density beams such as lasers and electron beams offer several advantages including precision, narrow fusion zones, and narrow heat affected zones (HAZ) that consequently result in reduced part distortion when compared to traditional joining processes. When high energy-density beams are combined with the design freedom offered by additive manufacturing (AM), or a layer-by-layer part fabrication process, it becomes possible to manufacture complex multi-material parts with improved joint characteristics resulting from controlled process parameters. Complex multi-material parts can be achieved that have tremendous impact on applications ranging from nuclear power plant components to repair applications. This research explores the feasibility of joining Inconel 718 with 316L Stainless Steel, and vice versa, by utilizing electron beam melting (EBM) additive manufacturing, a class of powder bed fusion technology. The use of this process can help avoid the use of filler materials, provides an evacuated processing environment resulting in limited contamination of oxides and nitrides, and can provide a high quality metallurgical joint while minimizing the thermal damage to surrounding material. Multi-material components were fabricated and the joint interfaces were characterized. Assessments of the interfaces revealed minimized thermal effects from the process and finer weld joints.
\end{abstract}

Keywords: additive manufacturing, electron beam melting, multi-material, Inconel 718, 316L 


\section{Joining of Inconel 718 and 316 Stainless Steel using Electron Beam Melting additive manufacturing technology}

\section{Introduction}

Multi-material parts have been achieved by a variety of joining techniques including brazing, welding, and soldering; however, the metallurgical characteristics of traditional welding processes can result in increased number of precipitates, intermetallics, and distortion of the weld interface that are detrimental to part properties. High quality joints have been achieved using high energy-density beams such as lasers and electron beams, which offer several advantages including precision, narrow fusion zones, and narrow heat affected zones. Today, additive manufacturing (AM) technologies, or layer-by-layer part production, have taken advantage of high energy-density beams and have been used in past research efforts [1] to join dissimilar metals. This research explores the joining of Inconel 718 with 316L Stainless Steel by utilizing electron beam melting additive manufacturing (EBM), a class of powder bed fusion technology, to demonstrate the feasibility of producing parts useful for nuclear fission applications.

Light water reactors experience a large variety of temperatures, pressures, dose, and stress levels making the deployment of a large number of materials necessary where a specific material is chosen (steel, nickel base alloys, Zr-alloys) for each condition and component. While many challenges exist in manufacturing nuclear reactors and components, a prevalent challenge is the joining of dissimilar materials and the transition from one material to another. Traditionally, welding is used with an established welding procedure termed black and white welding, where a filler material is usually of an additional metal alloy that has an intermediary coefficient of thermal expansion (CTE) of the two parts to be joined [2]. The welding of metals will often leave a microstructural imprint with defined features such as a fusion zone (FZ), unmelted zone (UZ), heat affected zone (HAZ) and a thermo-mechanically affected zone (TMAZ), which needs to be post-weld heat treated to minimize precipitation or segregation of phases that could reduce the mechanical or corrosive resistance of the material [3] [4]. The materials of interest in this study were Inconel 718 and 316L Stainless Steel due to their applicability in pressure tubes for nuclear fission reactors [2].

Inconel 718 (IN718) is a precipitation hardened nickel-based alloy used in gas turbines, nuclear reactors, and spacecraft structural components [5]. This alloy is widely used due to its high strength at moderate temperatures, corrosion and oxidation resistance, and its creep and 
fatigue resistance properties [6]. 316L Stainless Steel (316L SS), is an alloy used in steam generating power plants and nuclear reactors [7] due to its low corrosion rate, which is a consequence of the duplex oxide film created by an inner chromium oxide region and an outer mixed iron-nickel oxide region [8]. The main aspect to consider when welding Inconel alloys is their affinity to precipitate and form $\alpha$-chromium precipitates and $\mathrm{Nb}$-rich phases that can be present as brittle interdendritic areas, which have a detrimental effect on weldability and mechanical properties [9]. Inconel 718 has susceptibility of hot cracking in HAZ weld areas, which implies the need for heat treatments prior and post welding [5]. When brazing stainless steel to nickel-based alloys, high temperature melting point powder precursor is added to a braze filler as a means to achieve the desired capillary effect of the mixture and to fill large defects, such as wide cracks, at the expense of changing alloy composition within the filled regions [10]. As a result, modified part designs are necessary to accommodate for minimum joint clearances (less than $100 \mu \mathrm{m}$ ), which can become more expensive and difficult to meet when manufacturing mating parts that have non-standard geometries. Thus, by utilizing AM, it may be possible to take advantage of high energy-density beam processes to mitigate the use of filler metals and create a fine microstructural bond for the production of highly complex parts.

The notion of fabrication, or joining, of dissimilar materials utilizing AM is not a foreign concept and has been demonstrated by various researchers and different AM technologies. The joining of two non-compatible alloys by modifying the material's chemistry in a layer-by-layer fashion and creating a functional gradient has been done with laser engineering net shaping (LENS) [11]. Laser based AM-selective laser melting (SLM) has also been used to produce more functionally graded materials for the process of cladding dissimilar alloys [12]. Although the fabrication of functionally graded materials using AM has been demonstrated by previous research [13] [14], fabrication of functionally graded materials by powder bed fusion is still a challenge due to the required powder mixing that may render a batch of material unusable. The notion of using AM technologies for repair of Nickel based superalloys has previously been investigated and has shown promise in achieving advantageous microstructural features such as single crystal epitaxy from a substrate [15]. There has been a noteworthy advancement in the ability to control and tailor the microstructure of material fabricated via processes such as EBM for part fabrication and repair [16]. Previous efforts [1] have demonstrated the feasibility of multi-material fabrication using EBM by joining copper and Ti-6Al-4V parts, which was 
achieved by developing a fabrication method that included multiple fabrication sequences. The work demonstrated the feasibility of joining dissimilar metal systems with a mechanically functional interface via EBM [9]. The research presented in this manuscript explores the feasibility of joining IN718 with 316L SS by utilizing selective electron beam melting additive manufacturing (EBM), a powder bed fusion technology. Being a high energy-density beam process, EBM has the capability to bypass commonly used filler materials to achieve a functional interface. In this research, multi-material components were fabricated and the joint interfaces were characterized. Assessments of the interfaces revealed minimized thermal effects (e.g. reduced presence of precipitates) from the process and finer weld joints (HAZ depth as small as $443 \pm 56 \mu \mathrm{m})$ when compared to traditional welding processes.

\section{Methodology}

\subsection{Materials}

For this project the alloy systems were chosen due their shared parent austenitic FCC crystal structure with similar lattice parameters that were close to unity. Additionally, the CTE for both materials were similar and only had a small difference: IN718 has a linear CTE of 13.0 $\mu \mathrm{m} / \mathrm{m}-{ }^{\circ} \mathrm{C}$ and $316 \mathrm{~L} \mathrm{SS}$ has a linear CTE of $16 \mu \mathrm{m} / \mathrm{m}-{ }^{\circ} \mathrm{C}$ (both at a temperature of $100^{\circ} \mathrm{C}$ ) [17] [18]. IN718 was obtained in powder form from AP\&C, a division of Raymor Industries Inc (Boisbriand, Québec). Precursor powder for 316L SS was obtained from Sandvik (Stockholm, Sweden). Sufficient powder was obtained to fabricate specimens in sizes of $70 \mathrm{~mm}$ by $70 \mathrm{~mm}$ by $15 \mathrm{~mm}$ (where the shortest length represents the build direction). Substrates of each corresponding material were also obtained in sizes of approximately $100 \mathrm{~mm}$ by $100 \mathrm{~mm}$ by 15 $\mathrm{mm}$.

\subsection{Fabrication}

Part fabrication was achieved using an EBM S12 system from ARCAM AB (ARCAM AB, Mondal, Sweden). The EBM process has been described by previous research [1] [19]. The fundamentals of the process consist in the repetition of five steps: 1) preheat of the layer to be fabricated, 2) melt of the contours, or the silhouette/outline, of the two dimensional figure, 3) melt of the interior of the parts, 4) lowering of the table one layer thickness (chosen to be $70 \mu \mathrm{m}$ for this study), and 5) raking of powder to deposit a uniform layer. At the time of writing this 
manuscript, part fabrication using an S12 system has been certified by ARCAM AB for Ti-6Al4V, Ti-6Al-4V ELI, pure titanium, and Co-Cr-Mo. For this reason, development of parameters for the pre-heat and melt themes was necessary to achieve successful fabrication of IN718 and 316L SS precursor powder. A subsized vat was utilized to speed up the development of processing parameters and facilitate the preparation time for experimentation. The subsized fabrication setup consisted of a cylindrical column instead of the conventional rectangular fabrication area and reduced fabrication height. The subsized setup achieves a $96 \%$ reduction in fabrication volume from the reduced fabrication area and vat height that in turn reduces system dead time, preparation time, and the volume of material utilized for fabrication. Specifics on the subsized fabrication setup have been explained previously by Medina [20]. Fabrication began with IN718, where powder deposition, pre-heat, and melt theme parameters were optimized for fabrication atop 316L SS substrates.

The parameters modified for successful fabrication included beam speed, beam current, beam focus, and fabrication temperature. Fabrication parameters for IN718 were: beam speed= $918 \mathrm{~mm} / \mathrm{s}$, beam current $=12 \mathrm{~mA}$, beam focus $=22 \mathrm{~mA}$, and fabrication temperature $=920{ }^{\circ} \mathrm{C}$. Once optimal parameters were achieved for IN718, the powder precursor was fully removed from the system, which was followed by thorough cleaning to remove any residual material and prevent contamination. Upon cleaning, the system was loaded with 316L SS precursor powder and processing metrics were developed while fabricating onto IN718 substrates. Successful parameters for the $316 \mathrm{~L} \mathrm{SS}$ were: beam speed $=4350 \mathrm{~mm} / \mathrm{s}$, beam current $=17 \mathrm{~mA}$, beam focus $=$ $1 \mathrm{~mA}$, and beam temperature $=950{ }^{\circ} \mathrm{C}$. These parameters resulted in processing times of $2.5 \mathrm{hrs}$ and $2 \mathrm{hrs}$ for the $70 \mathrm{~mm}$ by $70 \mathrm{~mm}$ by $15 \mathrm{~mm}$ specimens fabricated using IN718 and 316L SS, respectively.

\subsection{Characterization}

The as-fabricated specimens were initially sectioned via waterjet and further sectioning was achieved using an abrasive rotary cutting machine with alumina blades. The as-fabricated specimens were sectioned into $\sim 15 \mathrm{~mm}$ cubes for metallographic analysis. Upon sectioning, the specimens were mounted in a castable epoxy resin mount. Specimens were then ground with $\mathrm{SiC}$ grit paper and polished with diamond and $\mathrm{Al}_{2} \mathrm{O}_{3}$ slurries. The polished specimens were subsequently cleaned in ultrasonic baths of isopropanol in-between steps. The specimens were 
finally polished with colloidal silica and ultrasonically cleaned in methanol. Once ready, the specimens were etched by a two tiered process to reveal the microstructure. Initially specimens were immersed in Glyceregia that was comprised of $30 \mathrm{~mL} \mathrm{HCl}, 20 \mathrm{~mL}$ glycerol, and $10 \mathrm{~mL}$ $\mathrm{HNO}_{3}$. The specimens then underwent electrolytic etching under a solution consisting of $70 \mathrm{~mL}$ $\mathrm{H}_{3} \mathrm{PO}_{4}$ and $30 \mathrm{~mL} \mathrm{H} \mathrm{H}_{2} \mathrm{O}(\mathrm{DI})$ at $5 \mathrm{~V}$. A two part etching process was used to reveal the $\mathrm{HAZ}$ in the IN718 substrate (utilized to reveal $\delta-\mathrm{Ni}_{3} \mathrm{Nb}$ ), which consisted of immersing the sample in Glyceregia for 60 s followed by electrolytic etching with a solution composed of $5 \mathrm{~mL} \mathrm{HF}, 10 \mathrm{~mL}$ glycerol, $30 \mathrm{~mL}$ ethanol, and $55 \mathrm{~mL} \mathrm{H}_{2} \mathrm{O}$ at $9 \mathrm{~V}$.

The microstructures of the samples were examined with brightfield optical microscopy utilizing a Reichert MEF4 A/M inverted metallographic system. Additional assessment of specimens was done utilizing an FEI Quanta 3D scanning electron microscope (SEM) with a field emission gun equipped with Oxford Instruments energy dispersive X-ray spectroscopy. Electron backscatter diffraction (EBSD) was done in parallel to assess the grain structure of the material at the interface. The prepared specimens underwent examination with X-Ray diffraction (XRD) using a $\mathrm{CuK} \alpha \mathrm{X}$-Ray source. XRD spectrums were collected from samples at the joint interface, 4 millimeters and 10 millimeters from the interface from both the substrate and the fabricated part. All micrographs attained and shown in this manuscript are oriented parallel to the build direction ( $\mathrm{XZ}$ plane) where the build direction runs from the bottom to the top of the micrographs.

Specimens prepared for optical microscopy were further prepared for microhardness testing by the removal of the epoxy resin to ensure secure placement and fixation. Vickers microindentation was performed with a Struers Duramin A-300 microindentaion system (Cleveland, $\mathrm{OH}$ ) with a $300 \mathrm{~g}$ force and a $15 \mathrm{~s}$ dwell time. Two measurements were obtained at each quarter millimeter approximately four millimeters from the interface into the substrate and three millimeters from the interface into the build direction.

\section{Results and Discussion}

\subsection{As-Received Materials}

The IN718 powder used in this study had a spherical morphology with an average particle size of $47 \pm 23 \mu \mathrm{m}$ and a range of $18-117 \mu \mathrm{m}$. The 316L SS powder had rough spherical morphology with satellite particles protruding from powder surfaces [21]. The average particle 
size was measured to be $50 \pm 23 \mu \mathrm{m}$ with a range of $17-110 \mu \mathrm{m}$. SEM images of the powders can be seen in Figure 1. The chemistries for the substrates can be seen in Table 1.

The microstructures of the substrates used for fabrication can be seen in Figure 2. The microstructure of a representative 316L SS substrate (Figure 2a) revealed equiaxed grains and annealing twins. There were some observable $\alpha$-ferrite stringers that are indicative microstructure of hot rolled materials. The as-received microstructure of the hot rolled IN718 substrate (Figure $2 b$ ) revealed a standard equiaxed microstructure with slightly elongated grains. Some bands, or "stringers", of secondary phases are apparent in the microstructure, which correspond to precipitates and carbides. Both microstructures are indicative of hot rolled processed substrates. XRD spectra of both substrates revealed texture in the (111) plane. The acquired spectra of the $316 \mathrm{~L}$ SS substrate revealed $\gamma_{\mathrm{Fe}}$-Austenite (FCC) with $a=3.60 \AA$. The spectra of the IN718 substrate revealed $\gamma_{\mathrm{Ni}} \mathrm{FCC}$ with a=3.62 $\AA$, and $\gamma$ ' $-\mathrm{Ni}_{3} \mathrm{Nb}(\mathrm{BCT})$ with $\mathrm{a}=3.60 \AA$, c=7.41 $\AA$. The texturing in the (111) plane is standard of hot rolled FCC metals.

Table 1. Chemical composition of Powders

\begin{tabular}{|l|c|c|c|c|c|c|c|c|c|c|c|c|}
\hline & $\% \mathrm{Ni}$ & $\% \mathrm{Fe}$ & $\% \mathrm{Cr}$ & $\% \mathrm{Nb}+\mathrm{Ta}$ & $\% \mathrm{Mo}$ & $\% \mathrm{Ti}$ & $\% \mathrm{Al}$ & $\% \mathrm{Mn}$ & $\% \mathrm{Si}$ & $\% \mathrm{C}$ & $\% \mathrm{P}$ & $\% \mathrm{~S}$ \\
\hline $\begin{array}{l}\text { IN 718 } \\
\text { powder }\end{array}$ & 52.5 & 18.58 & 19.1 & 5.04 & 2.95 & 0.91 & 0.58 & 0.05 & 0.13 & 0.03 & 0.004 & 0.001 \\
\hline $\begin{array}{l}316 \mathrm{LSS} \\
\text { powder }\end{array}$ & 10.5 & 69.85 & 16.6 & $\mathrm{~N} / \mathrm{A}$ & 2.2 & $\mathrm{~N} / \mathrm{A}$ & $\mathrm{N} / \mathrm{A}$ & $\mathrm{N} / \mathrm{A}$ & 0.8 & 0.03 & 0.02 & 0.01 \\
\hline
\end{tabular}



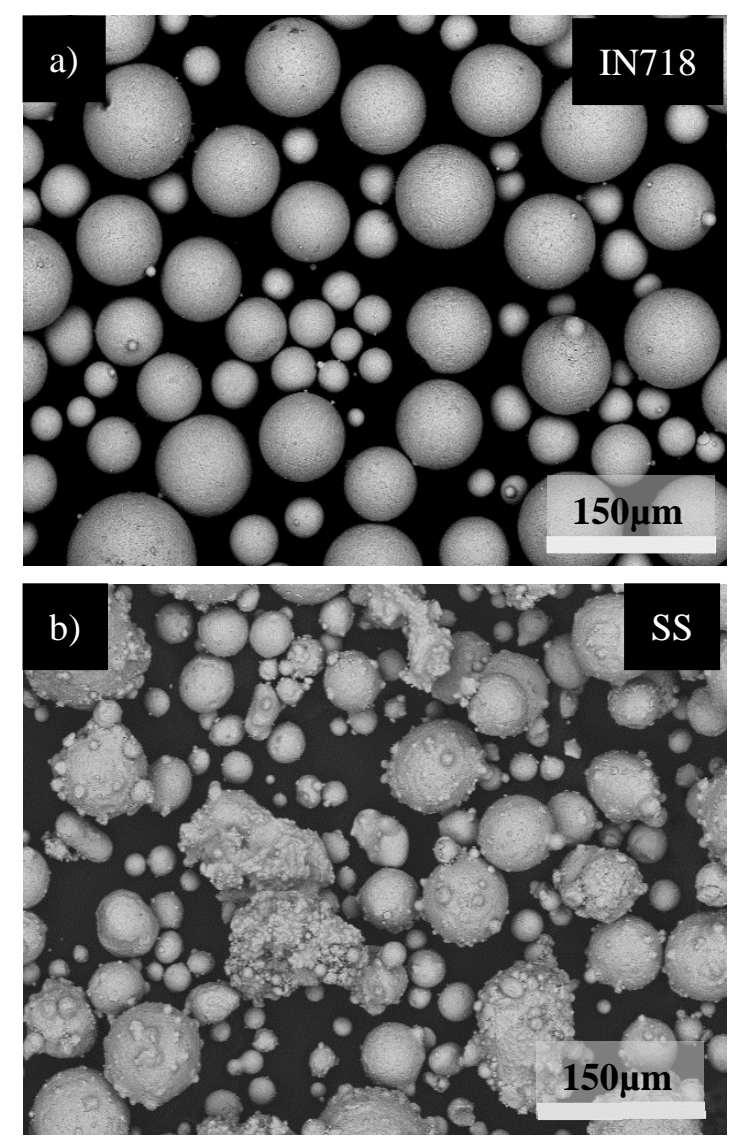

Figure 1 Micrographs of the IN718 (a) and 316L SS (b) as-received precursor powder 

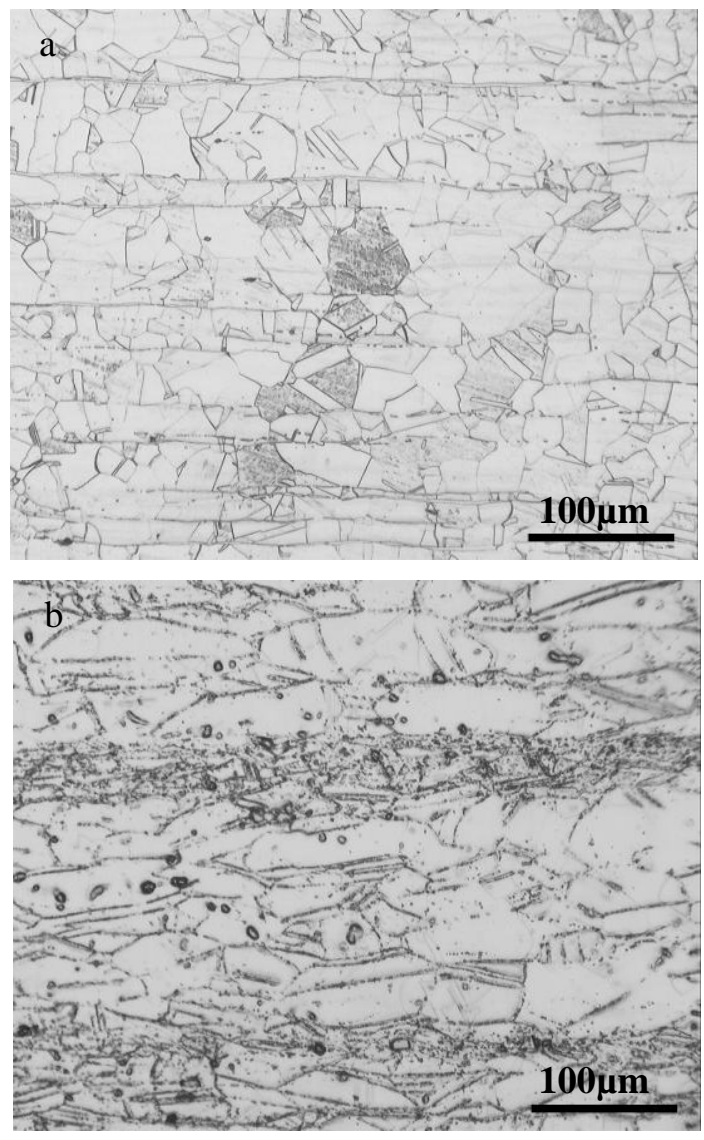

Figure 2 Micrographs of as-received substrate microstructures utilyzed for fabrication.

Hot rolled 316L SS with equiaxed grains shown in (a). Hot rolled IN718 shown in (b)

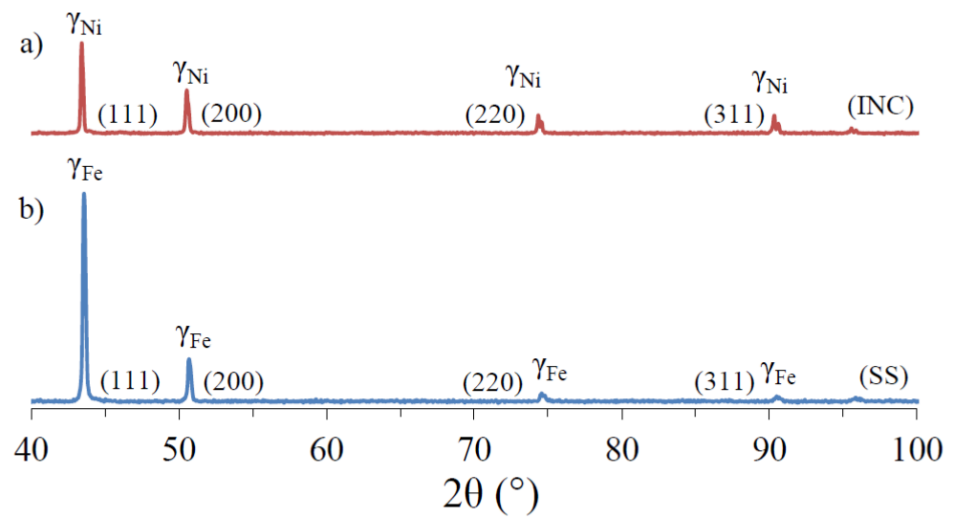

Figure 3 XRD Spectra for theIN718 and 316L SS substrates. Spectra shows texturing with respect to the (111) plane. 


\subsection{Inconel 718 Fabricated Onto 316L Stainless Steel Substrate}

Microstructural features will be described by the following terminology: fabricated material, or the resulting AM deposit (FM), fusion zone (FZ), un-melted zone (UZ), and the heat-affected zone (HAZ). The FM microstructure for IN718 can be observed in Figure 4. The FM showed an apparent columnar grain structure, which is most visible in Figure $4 \mathrm{~b}$ along with the presence of precipitates that were observed in both intragranualar and intergranular sites. Previous work has shown that the intragranular precipitates forming in EBM-fabricated IN718 are most likely $\gamma$ " precipitates [19]. The formation of $\delta$ was strongly considered in this investigation, and the high likelihood of its formation in the FM has been discussed in literature [22] [23]. The presence of $\delta$ and other TCP phases was not apparent in our specimens, but is believed to be present in a finer scale.

Initial evaluation of the IN718/SS 316L interface, Figure 4c, revealed no apparent porosity or cracking throughout the specimens. The interface reveals a continuous interface with shared grains in the FM and substrate, observed in Figure 4c and Figure 4d. Further inspection of the interface at several sites revealed grains growing in a columnar array from the substrate into the FM. The EBSD analyses revealed a distinct texture of $\langle 001\rangle$ in the build direction. This texturing has been previously observed in EBM-fabricated IN718 work done by Strondl et al. and Acharya et al. [23] [15]. This preferred growth direction is common and expected in materials that solidify with an FCC structure [24]. The notable columnar growth is commonly seen in metals fabricated by EBM [1] [19]. Globular precipitates continue to form in decreasing density approximately $150 \mu \mathrm{m}$ into the FM from the interface (Figure $4 \mathrm{c}$ ). Immediately above the interface there is a dense area of globular precipitates sized $\sim 50-75 \mu \mathrm{m}$ that can be more readily observed in Figure 4d. The interface here revealed no apparent features from mixing or dilution of the substrate and the fabricated material due to the lack of discrete features around the interface. The substrate microstructure of the HAZ post-fabrication can be seen in Figure 6. The HAZ had an average penetration depth of $2.61 \pm 0.43 \mathrm{~mm}$ into the substrate. The features observed from the interface and HAZ are smaller in comparison to classic joining techniques, such as gas tungsten arc welding (GTAW) [4]. The feature size of the interface and HAZ were smaller and comparable to that of the FZ and HAZ from electron beam welding (EBW) of austenitic stainless steels [25]. 
Upon individual EDS point analysis the globular phases revealed themselves to contain enrichments of $\mathrm{Nb}$ and $\mathrm{Mo}$ and depletions in $\mathrm{Fe}, \mathrm{Ni}$, and $\mathrm{Cr}$. The precipitates are most likely niobium carbide (NbC), which coincides with results from others [9] [26] [27]. The presence of $\mathrm{NbC}$ in welds is common, but has shown to be detrimental to ductility, fracture toughness, and time dependent failure mechanisms (i.e. fatigue and creep rupture). EDS concentration mapping, Figure 7, revealed enrichments in $\mathrm{Nb}$ and Mo, with a few shared areas containing $\mathrm{C}$, both intergranularly and intragranularly. Along the majority of the boundary there was major depletion of $\mathrm{Fe}$, but select areas showed little to no reduction in $\mathrm{Ni}$ and $\mathrm{Cr}$ with no apparent enrichment. The intragaular areas of the map contain similar characteristics, except for the complete depletion of $\mathrm{Fe}, \mathrm{Ni}$, and $\mathrm{Cr}$ in the $\mathrm{Nb}$ and $\mathrm{Mo}$ enriched areas. The area immediately above the interface, $\sim 50 \mu \mathrm{m}$ in height, with spots of intense $\mathrm{Nb}$ and Mo concentration represents the presence of the fine phases seen in Figure $4 \mathrm{~b}$. The majority of fine phases also showed enrichment in $\mathrm{C}$ and depletions in $\mathrm{Fe}, \mathrm{Ni}$, and $\mathrm{Cr}$, thus are most likely $\mathrm{NbC}$.

Areas in which there is a large refractory concentration and no apparent $\mathrm{C}$ enrichment insinuates the presence of possible topographically close-packed (TCP) phases such as: Laves$(\mathrm{Fe}, \mathrm{Ni}, \mathrm{Cr})_{2}\left(\mathrm{Nb}, \mathrm{Mo}, \mathrm{Si}\right.$ ) (hexagonal) or $\delta-\mathrm{Ni}_{3} \mathrm{Nb}$ (orthorhombic) [28]. The presence of these $\mathrm{TCP}$ or the $\mathrm{NbC}$ in this region is due to the partitioning of $\mathrm{Nb}$ and Mo upon solidification. Increase in Fe concentration in the IN718 system leads to decreased solubility of $\mathrm{Nb}$ and Mo in the austenitic matrix. The increase of $\mathrm{Fe}$ via dilution further promotes the partitioning of $\mathrm{Nb}$ and Mo upon solidification. In addition, it has been shown that the higher concentration in Fe can be expected to promote the formation of Laves phase [28]. Further EDS point analysis revealed that there was enrichment in $\mathrm{Ni}, \mathrm{Fe}, \mathrm{Cr}, \mathrm{Nb}, \mathrm{Mo}$, and $\mathrm{Si}$ in some of these aforementioned precipitates. Analysis of the quantitative atomic percentages showed 2:1 ratio of (Fe, $\mathrm{Ni}, \mathrm{Cr}$ ):(Nb, Mo, $\mathrm{Si}$ ), insinuating the presence of Laves phase at the interface. Thus the majority of these fine phases will be $\mathrm{NbC}$ or $\mathrm{MoC}$ and some Laves phase. The presence of Laves phase, or several other low melting point phases, upon solidification generally leads to solidification cracking or grain boundary liquation in which cracking can occur.

Assessment of the microhardness at the substrate, interface, and FM in Figure 8 shows the change in hardness across the interface. The average hardness for the IN718 FM and the 316L SS substrate was $241 \pm 12 \mathrm{HV}$ and $148 \pm 11 \mathrm{HV}$, respectively. The hardness in the substrate is fairly consistent and shows no apparent change across the substrate in the HAZ. This lack of 
change is representative of the consistency in the mechanical properties irrelevant of the apparent change in the grain size. The interface/FZ had the lowest hardness $(\sim 135 \pm 8 \mathrm{HV})$ which could be attributed to the partitioning of $\mathrm{Nb}$ to form $\mathrm{NbC}$ leading to solute depletion and an absence of $\gamma$ ". In addition it should be noted that the hardness shows a steady increase with fabrication height, except past $2 \mathrm{~mm}$.

Figure 9 depicts XRD spectra of the FM that revealed strong texture in the (002) plane with the $\gamma_{\mathrm{Ni}}$-FCC with a=3.62 $\AA$. This texturing was different than the $316 \mathrm{~L} \mathrm{SS}$ substrate that showed a texture in the (111) plane, which was due to the preferred growth direction of FCC Nickel superalloys that are generally textured in the (001) plane [24]. The diffraction spectra correspond closely to previous work [19] for EBM-fabricated IN718.
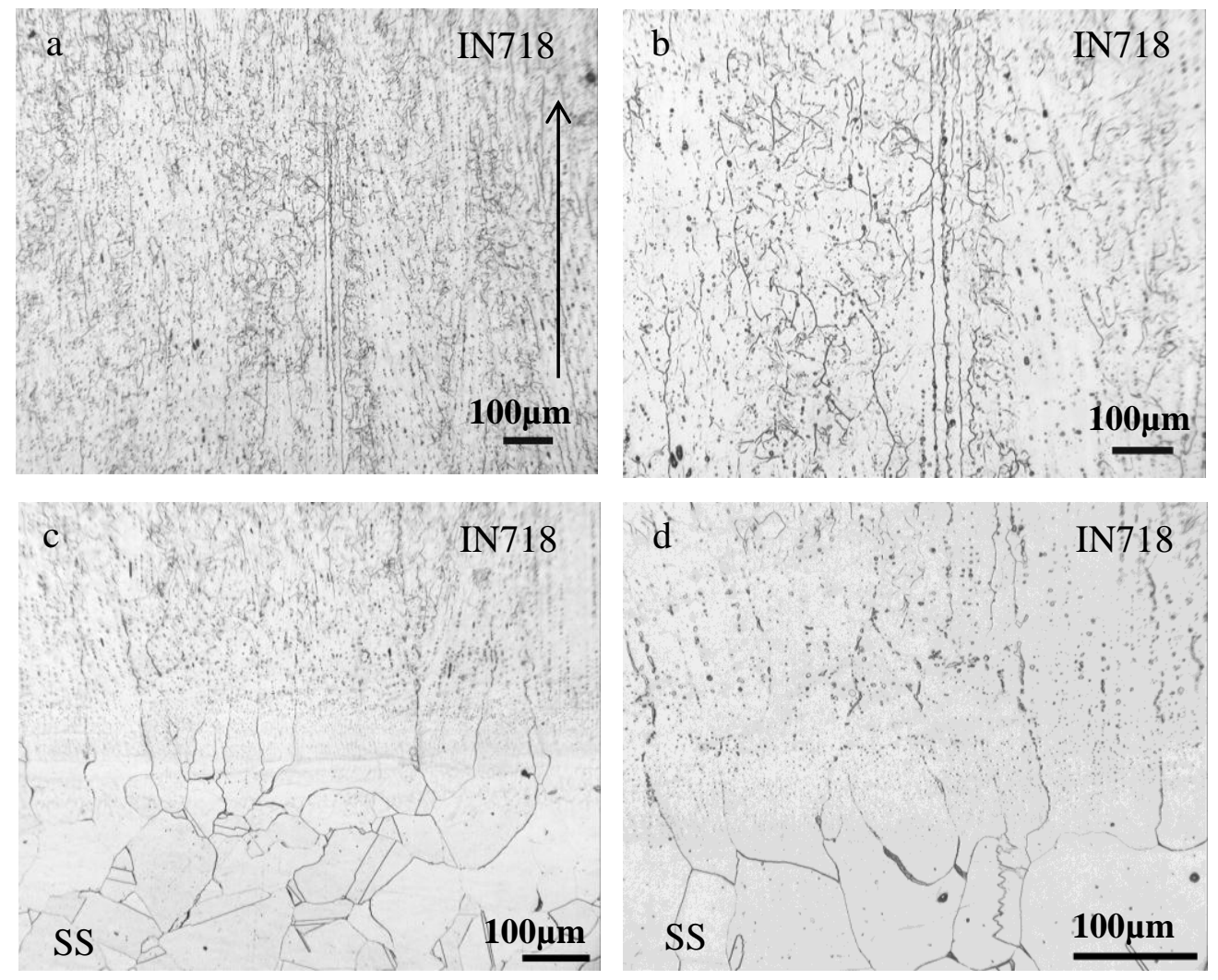

Figure 4 Microstructures of EBM-fabricated IN718. Micrograpgh (a) shows columnar nature of the grain structures. Micrograph (b) is a higher magnification image of themagnification of the grain structure. Micrographs of the joint interface for fabrcated IN718 onto 316L SS substrate joint interface are shown by (c) and (d). The arrow indicats the build direction. 

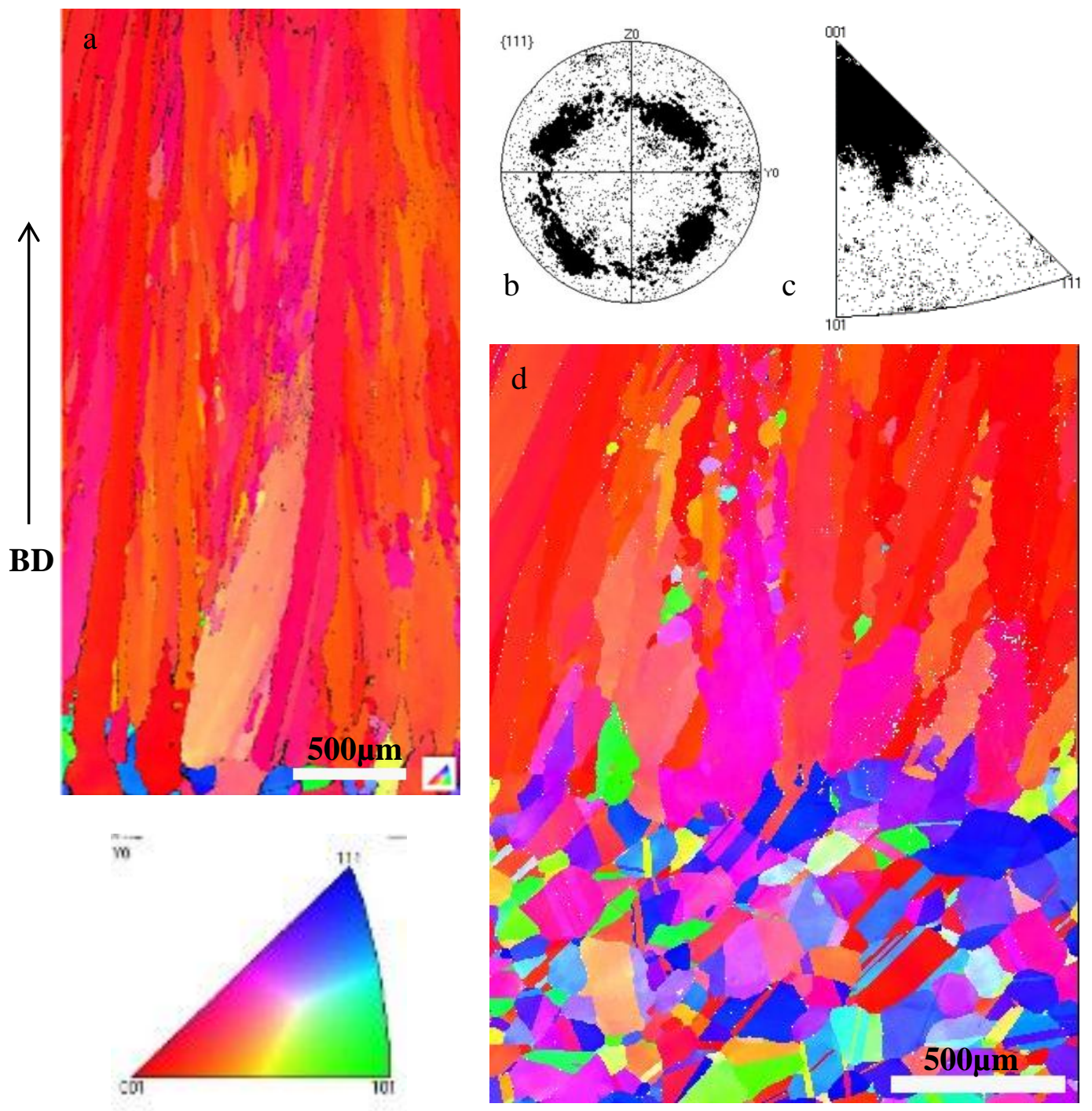

Figure 5 Micrograph (a) is an inverse pole figure(IPF) color map of the of the fabricated IN718 on 316L SS substrates with pole figures and inverse pole figures in (b) and (c) respectively. Fabrication shows large columnar grains and strong texturing in the [001] direction. Micrograph (d) is an IPF color map of the joint interface between the IN718 and 316L SS substrate. Markers in a) and d) are each 500 $\mu \mathrm{m}$. 


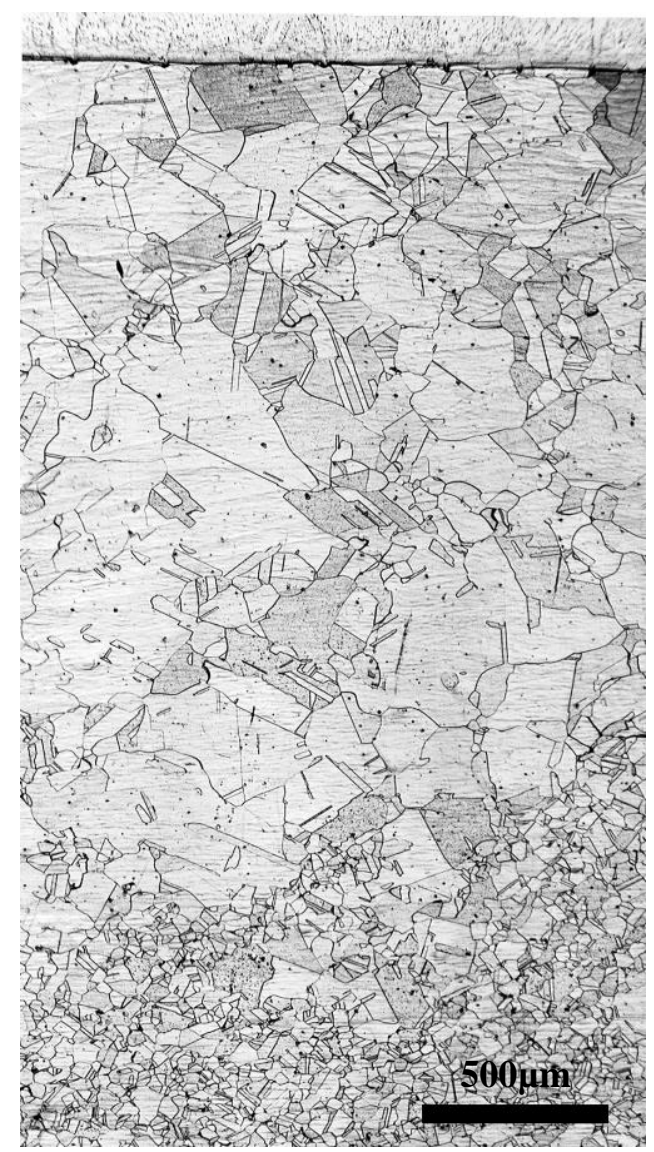

Figure 6 Micrographic reconstruction of the 316L SS substrate revealing the HAZ. The marker in the micrograph is $500 \mu \mathrm{m}$. 


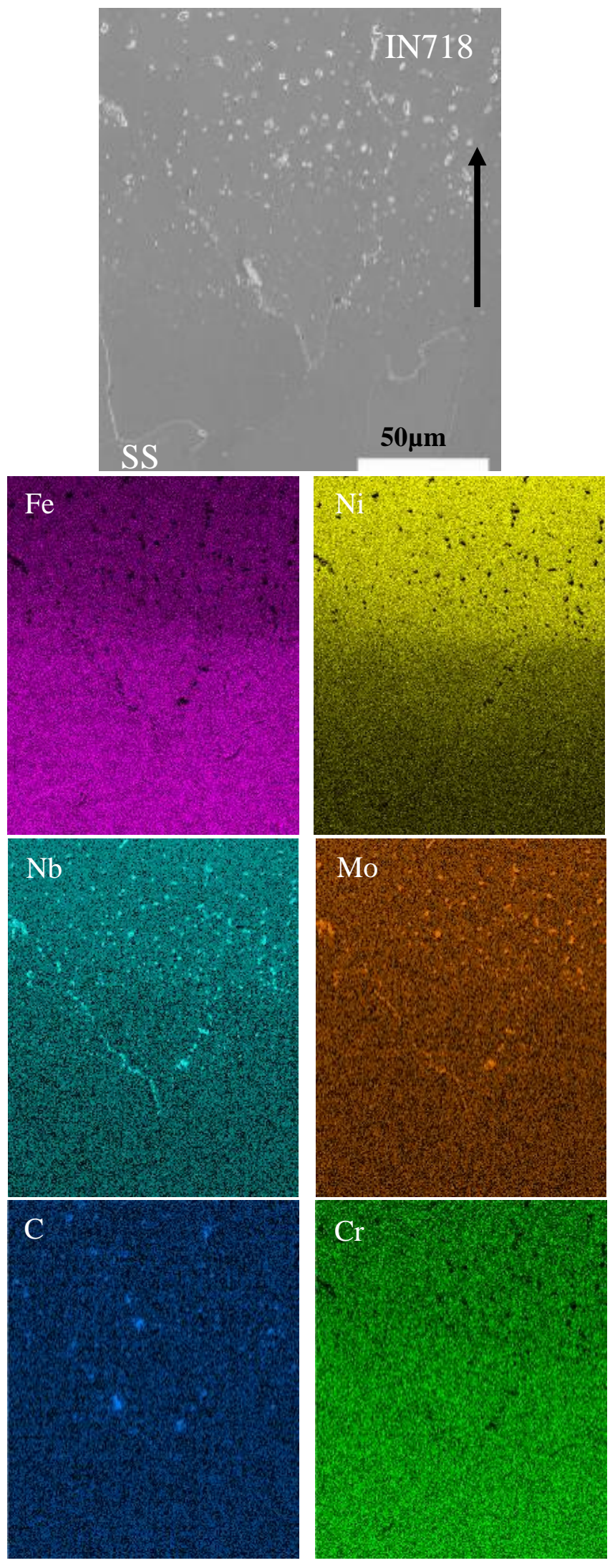

Figure 7 EDS elemental concentration map of fabrication interface for IN718 on 316 SS. Center micrograph shows the SEM image of scanned area, marker is $50 \mu \mathrm{m}$. Arrow represents build direction. 


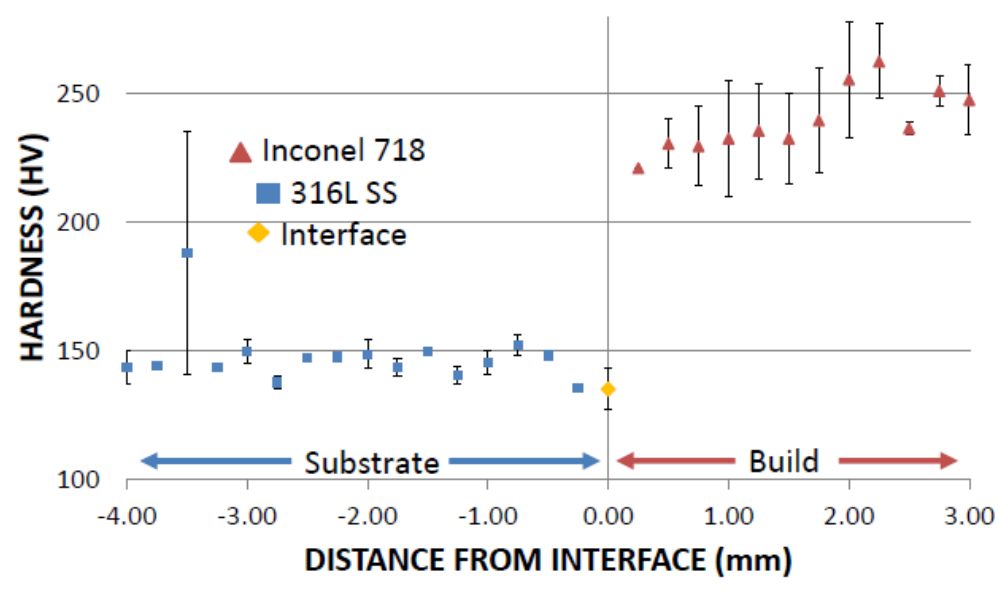

Figure 8 Microhardness across the interface of the fabricated IN718 on 316L SS.

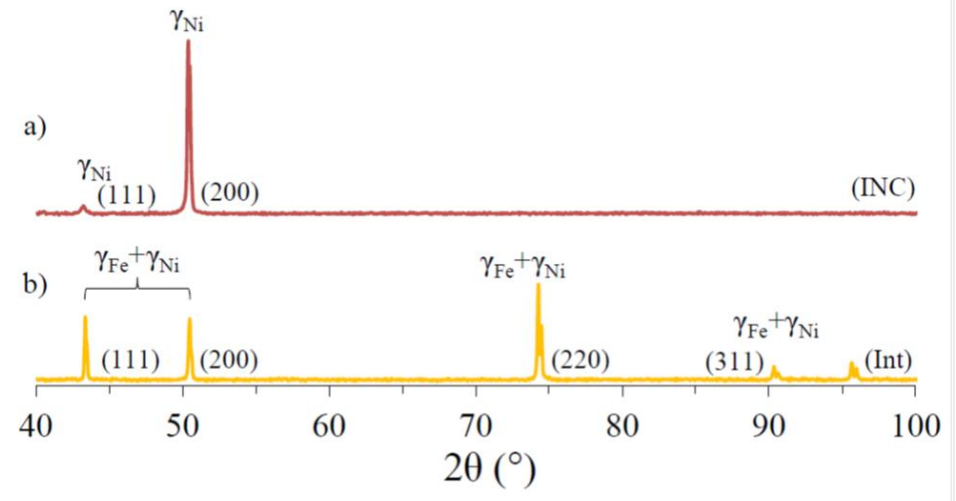

Figure 9 XRD spectra of fabricated IN718 on the 316L SS substrate. a) is spectra collected $10 \mathrm{~mm}$ from the interface in the fabricated IN718. Spectra b) was collected at the joint interface of the 316L SS substrate and the fabricated IN718.

\subsection{L Stainless Steel Fabricated Onto Inconel 718 Substrate}

The structure of the EBM-fabricated 316L SS revealed a columnar grain structure (Figure 10 and Figure 11) in contrast to an equiaxed microstructure that is typical of 316L SS. The FM showed the appearance of fabrication defects that are inherent to powder bed fusion additive manufacturing. Defects observed were of par-melted powder and unmelted/unconsolidated layers as seen in Figure 10a and Figure 10b, respectively. The microstructure of the 316L SS/IN718 interface showed many distinct features, as seen in Figure 10c and Figure 10d, and Figure 11, in 
contrast to the IN718/316L SS. The FZ had an average height of approximately $140 \pm 12 \mu \mathrm{m}$. There was apparent intergranular cracking that was present in the UZ (only the upper region), FZ, and the FM, which did not extend into the HAZ or the substrate. The longest crack within a representative area in the FM did not go farther than $\sim 364 \mu \mathrm{m}$ into the FM (from the FZ), and the average crack length was $148 \pm 56 \mu \mathrm{m}$. The FZ did not have a columnar nature like that of the IN718/316L SS, but had an elongated grain structure perpendicular to the build direction with well-defined heights spanning the entire interface (Figure 11d and Figure 10d). The grains had an average height of $\sim 57-72 \mu \mathrm{m}$ from the end of the UZ to the FM. The presence of many fine globular precipitates was found within the flat grains of the FZ. The region showed a trend of decreasing density along the build direction. In the UZ there also appeared to be interdendritic porosity and the formation of precipitates in mainly intragranular sites. The UZ had an average height of $132 \pm 8 \mu \mathrm{m}$. EBSD analysis of the interface and the FM (Figure 11a) also shows the grains growing preferentially in the <001> direction, with PF and IPF in Figure 11b and Figure 11c, respectively. It can be noted in both the IPF color map and the Euler color map that the grains in the fabricated material were growing epitaxially in a columnar fashion. In addition, the grains showed an angled growth $\sim 20^{\circ}$ from the normal of the interface, most likely due to the fabrication process. The EBSD of the interface also revealed that within the HAZ there was apparent grain growth, which can be more easily noted in the Euler map in Figure 11d.

The microstructure of the substrate post fabrication in the region beneath the interface can be observed in Figure 12. The substrate microstructure post fabrication did not only reveal a presence of carbides but did reveal acicular $\delta-\mathrm{Ni}_{3} \mathrm{Nb}$ phase, as seen in Figure 12 . The unattacked region beneath the interface was defined as the HAZ where this region showed an apparent absence of the acicular $\delta-\mathrm{Ni}_{3} \mathrm{Nb}$ phase. The lack of the $\delta$ phase can be explained by the heat exposure of this region above the $\delta$ solvus temperature, $996^{\circ} \mathrm{C}$. In addition, enlarged grain growth in this region can also be observed in the EBSD color maps in Figure 11d [29]. The HAZ had a depth of $443 \pm 56 \mu \mathrm{m}$.

EDS concentration mapping of the interface area were taken to examine the features in the FM, FZ, UZ, and the upper edge of the HAZ. Upon examination, the map revealed discrete steps of decreasing concentration of $\mathrm{Ni}$ and increasing $\mathrm{Fe}$ in the $\mathrm{FZ}$ along the build direction. It can be noted here that these discrete steps of changing concentration have the same height as the flat grains noted within the FZ seen in Figure 10c, Figure 10d, and Figure 11. The changes in 
concentration have been attributed here to the inherent layerwise process, or layer-by-layer processing that was set at $70 \mu \mathrm{m}$ for fabrication. This gradient can be explained due to the fact that the electron beam not only melts the deposited powder but a fraction of the underlying material as well. Thus, the initial layers will have a high concentration of major elements from the substrate and subsequently deposited layers will have a continually decreasing amount of these constituents as fabricaiton proceeds. This is also seen in the fabrication of Ti-6Al-4V on stainless steel substrates with initial fabrication layers of stabilized $\beta$ due to this mixing [30]. With the mixing of materials in the FZ, there was a dilution of the $\mathrm{Fe}$ and an increase in the $\mathrm{Ni}$, $\mathrm{Nb}$, and $\mathrm{Mo}$. The increased concentration of $\mathrm{Nb}$ with dilution of $\mathrm{Fe}$ in this region justify the presence of the fine globular precipitates due to the increased tendency for partitioning with increases in Fe. This precipitate heavy region is similar to the FZ in the IN718/316L SS specimen. In addition to the $\mathrm{Fe} / \mathrm{Ni}$ gradient in the $\mathrm{FZ}$, there appears to be an increased concentration of $\mathrm{C}$, thus making the enrichment of carbides within this region more apparent. This phenomenon has also been seen within the FZ of dissimilar welds consisting of austenitic stainless steels and $\mathrm{Nb}$ bearing nickel-based superalloys [9] [27].

Further EDS analysis of the FZ and the UZ revealed enrichment of Nb, Mo, and C. There were also distinct spots with a lack of depletion of $\mathrm{Fe}$ or $\mathrm{Ni}$ in the same regions where the refractory elements were enriched. This lack of depletion raises the notion that there may be Laves phase formation. EDS point analysis of the precipitates in the UZ revealed precipitates that contained enrichments in $\mathrm{Nb}, \mathrm{Mo}$, and $\mathrm{C}$, which are representative of carbide formation. EDS point analysis of the cracks in the upper FZ (region in low level of mixing from the substrate) revealed enrichment of $\mathrm{Cr}$ and $\mathrm{C}$. The formation of $\mathrm{M}_{23} \mathrm{C}_{6}$ carbides in intergranular sites can be observed during exposure of the material at elevated temperature ranges from $700^{\circ}$ to $900^{\circ} \mathrm{C}$. Prolonged exposure and enhanced precipitation of $\mathrm{M}_{23} \mathrm{C}_{6}$ can lead to the increased vulnerability of intergranular corrosion [31].

Cracks at the interface of the 316L SS/IN718 fabrication can be due to a combination of factors. Currently, it is suspected that the major cracks at the interface are due to several factors where a major contributor can be attributed to large thermal stresses brought upon from the differences of CTE between the FM and the substrate. The IN718 substrate has high stiffness at higher temperatures, thus, constricting substrates ability to warp, which resulted in the deformation of the substrate. The severity and morphology of cracking can be attributed to the 
phenomena in welded materials called ductility dip cracking (DDC). DDC occurs upon cooling when metals experience a drop, or a "dip", in ductility over a narrow temperature range that lies in between the solidus temperature and half of the solidus temperature. Cracking occurs on high angle and migrated grain boundaries that are straight or non-"tortuous" that are not pinned by the presence of a precipitate or secondary phase. It has been reported that DDC in the FZ and HAZ of fully austenitic and highly restrained weldments are most susceptible to this phenomena [31]. It should be noted that the degree of mechanical restraint increases with the microstructure of the weldment, the substrate in this case, being in precipitation hardened condition in contrast to a "softened" solution annealed condition [28]. It is important to note that there was some apparent warping in the substrate similar to that observed with previous attempts of IN718 fabrication onto austenitic SS substrates via EBM [32] [22]; however, the cracking in these substrates was not observed.

Microhardness of the substrate, interface and FM of the 316L SS/IN718 specimen can be seen in Figure 14. The average hardness for the 316L SS FM and the IN718 substrate was $184 \pm 11 \mathrm{HV}$ and $296 \pm 11 \mathrm{HV}$, respectively. Just below the interface $(<1000 \mu \mathrm{m})$ there is an immediate drop in hardness for the HAZ. In the remainder of the substrate, the material showed no appreciable change in hardness as the distance from the interface increases. In the 316L SS near the interface, $\sim 250 \mu \mathrm{m}$, there was a large decrease in the hardness but then remained relatively constant for the remainder of the fabrication height. The average hardness at the interface showed variable results $(\sim 267 \pm 27 \mathrm{HV})$, which could be explained by the different degrees of mixing that occurred in the FZ.

XRD spectra for the fabricated 316L SS onto the IN718 substrate at the interface, FM, and substrate are shown in Figure 15. The FM was strongly textured [200] and the XRD spectra at the interface and FM did not reveal the presence of any $\alpha$-ferrite (BCC) in the structure, insinuating a fully austenitic mode of solidification. It should be noted that a fully austenitic mode of solidification is generally more prone to hot cracking or interdendritic cracking during solidification [33]. The XRD spectra obtained in this work have been compared to mixtures of $\gamma_{\mathrm{Fe}}$ and $\alpha_{\mathrm{Fe}}[34]$ to verify the austenitic mode of solidification in the FM. 

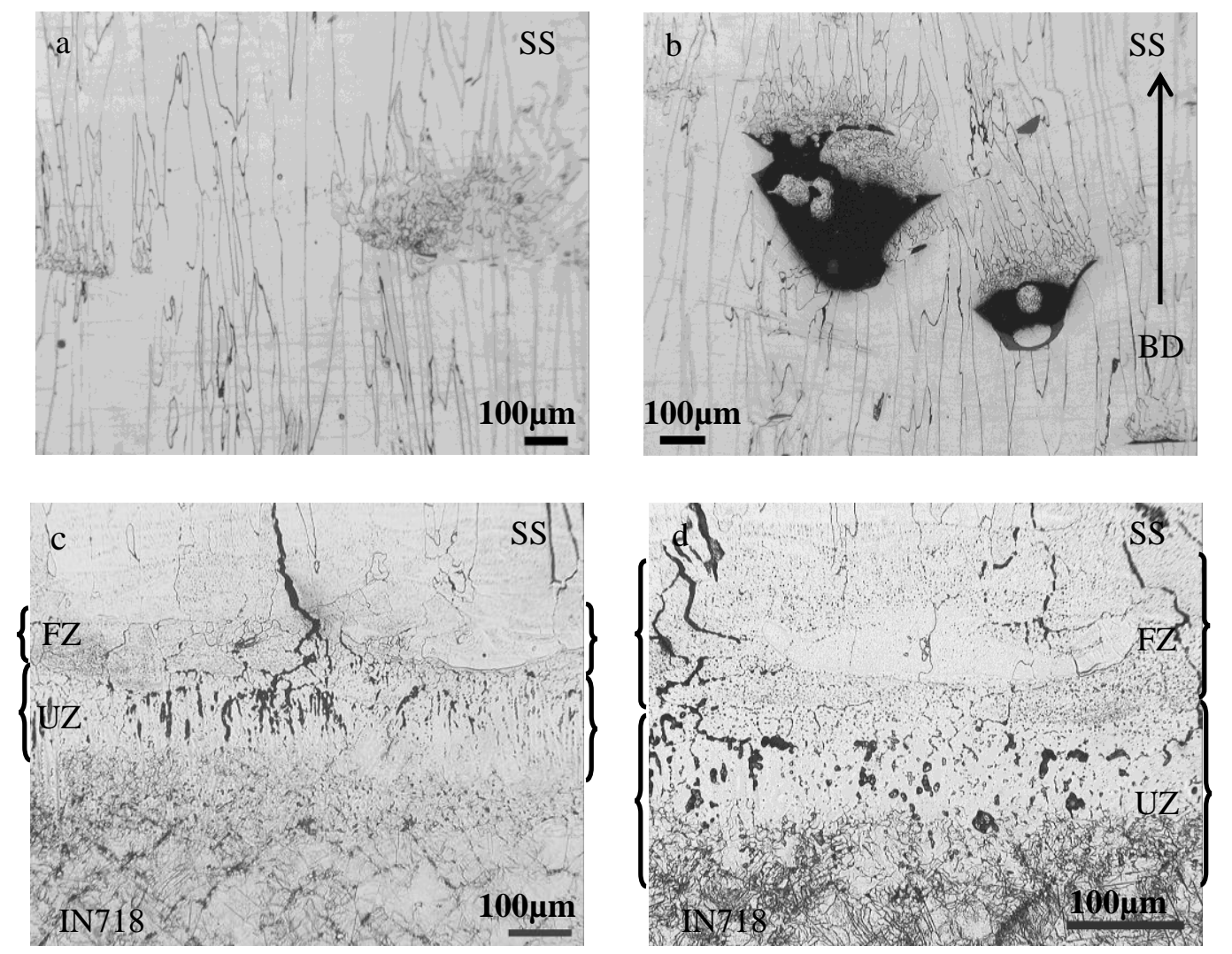

Figure 10 Micrographs of the fabricated 316L SS. Micrograph (a) and (b) shows defects of par-melted and un-melted layers with entrapped powder. Microstructures of the fabricated 316L Stainless Steel on the IN718 substrate. Brackets on the upper and lower part of the micrographs define the FZ and UZ. Arrow shows build direction. 

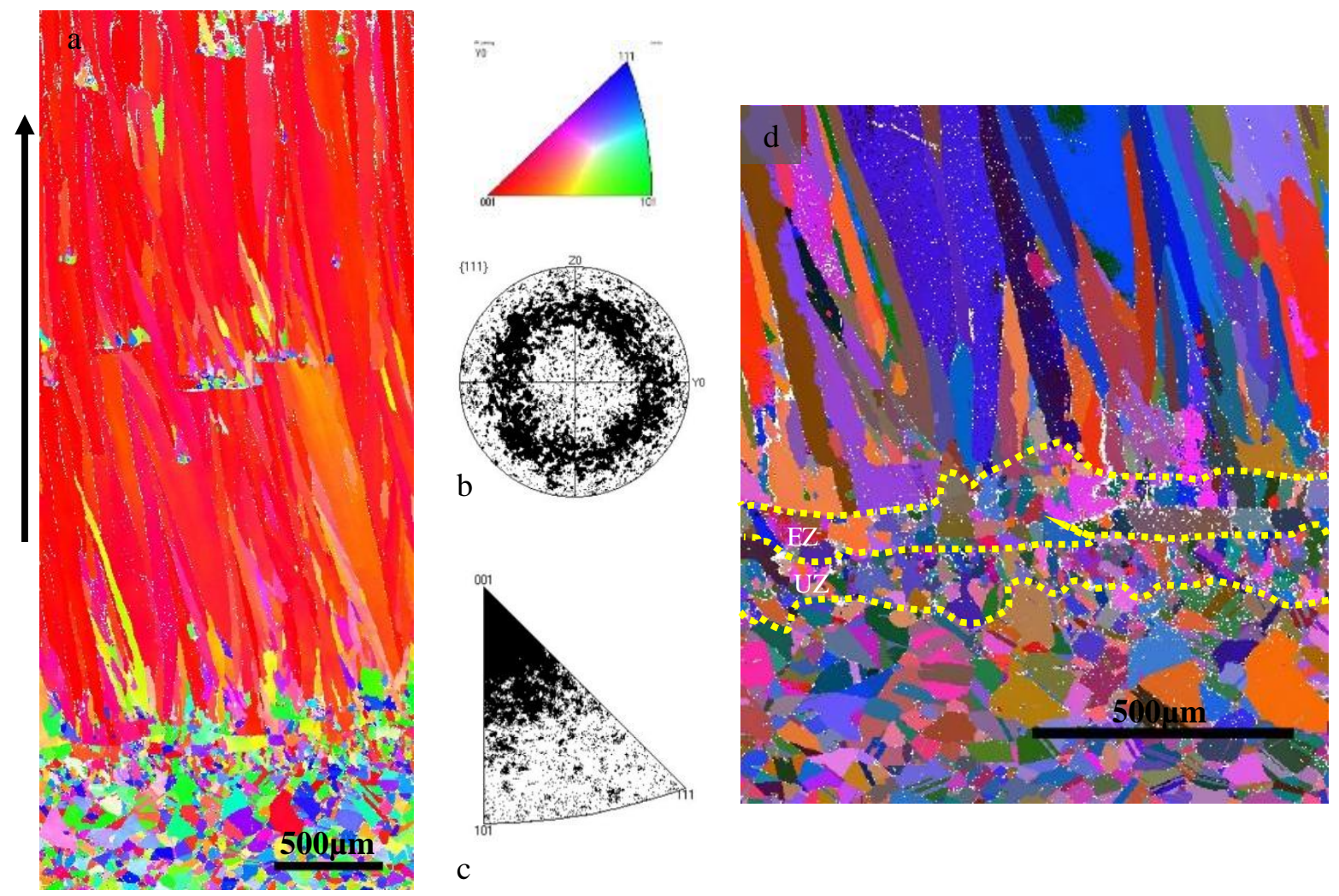

Figure 11 EBSD of the fabricated 316L SS on IN718 and of the interface. The inverse pole figure (IPF) color map (a) shows preferred texture in the $\langle 001\rangle$ direction. The pole figure (b) and IPF distribution (c) show the dispersion of orientation of the FM. A Euler color map of the interface at higher magnification is shown in d. The FZ and $U Z$ are delineated by dashed lines on the Euler color map 

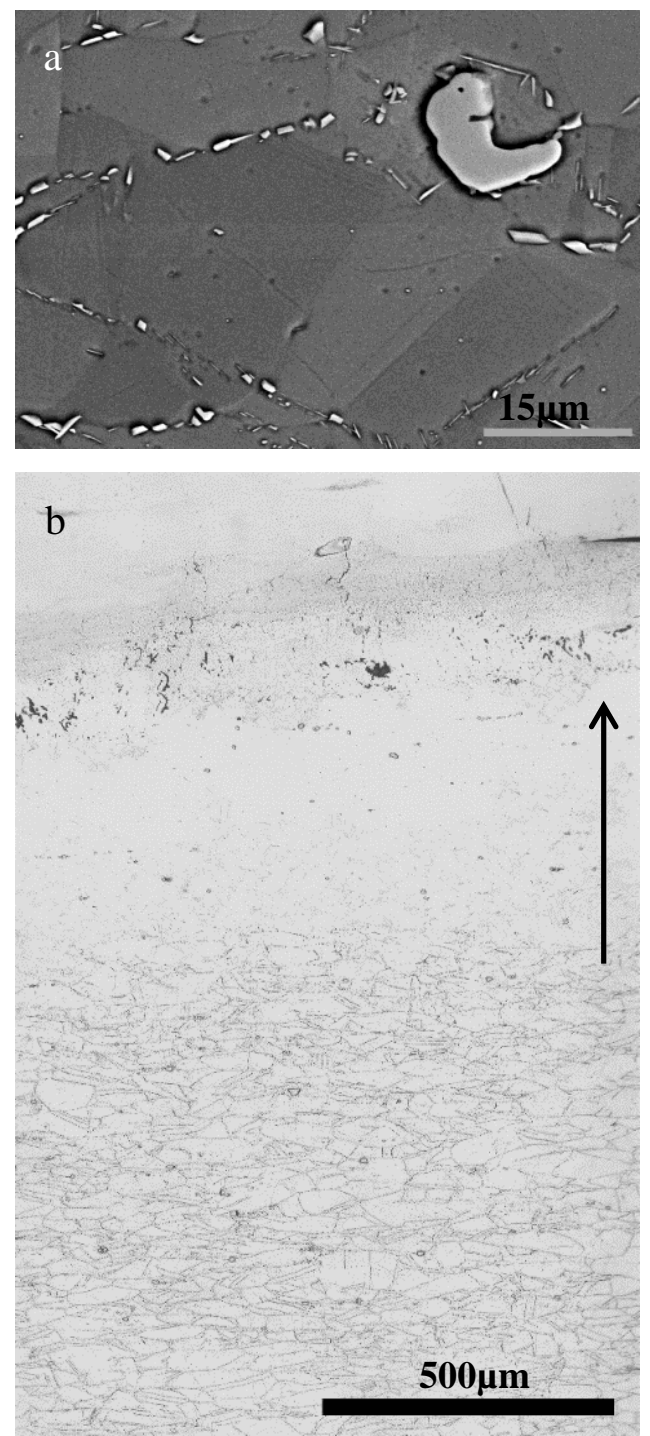

Figure 12 Micrograph (a) shows a backscatter electron image of dispersed acicular $\delta$ phase. Micrographic reconstruction of IN718 substrate post-fabrication showing defined HAZ. The arrow indicates build direction. 


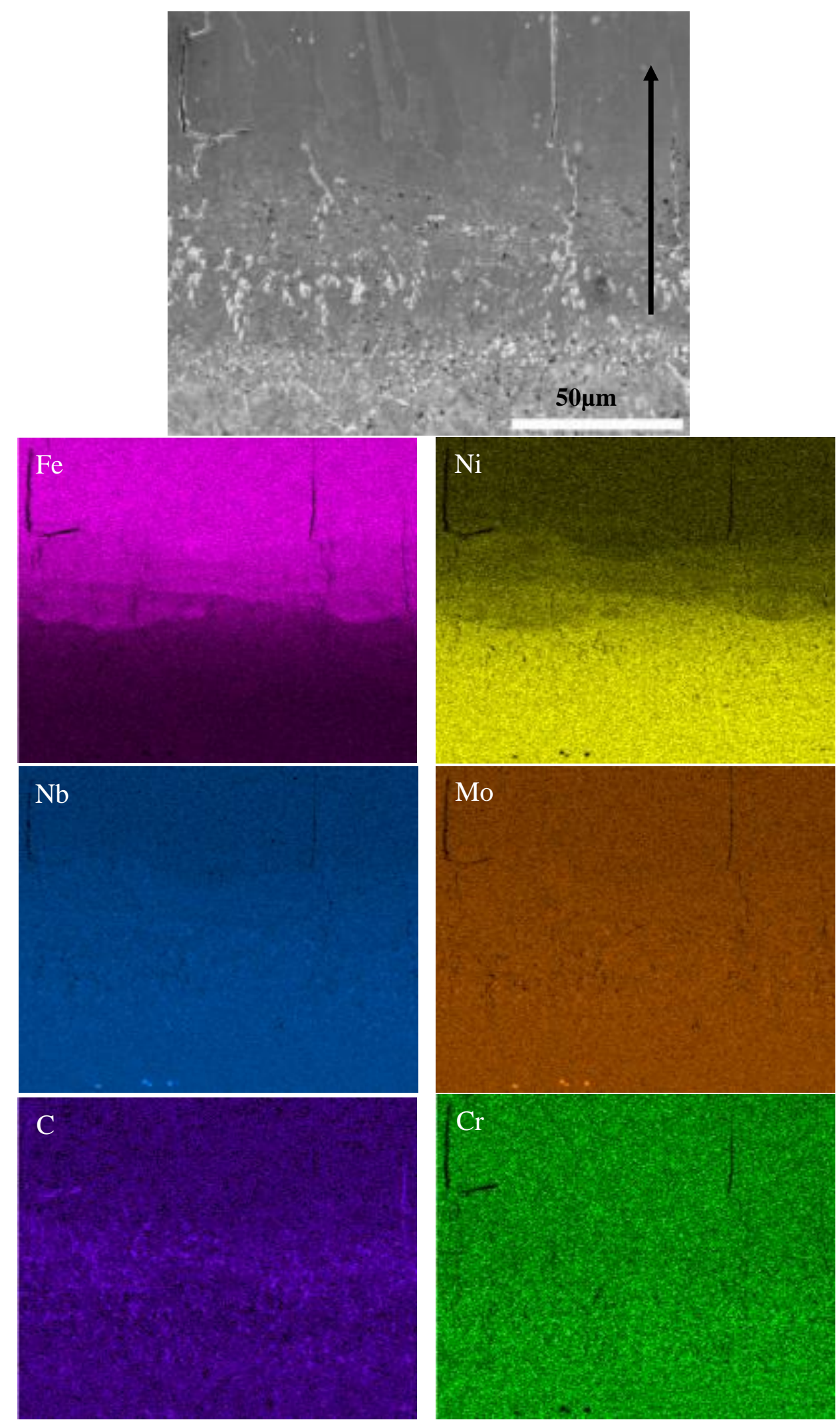

Figure 13 EDS elemental concentration map of fabrication interface for 316L SS on IN718 the shared UZ and FZ region. Marker. Arrow indicates build direction. 


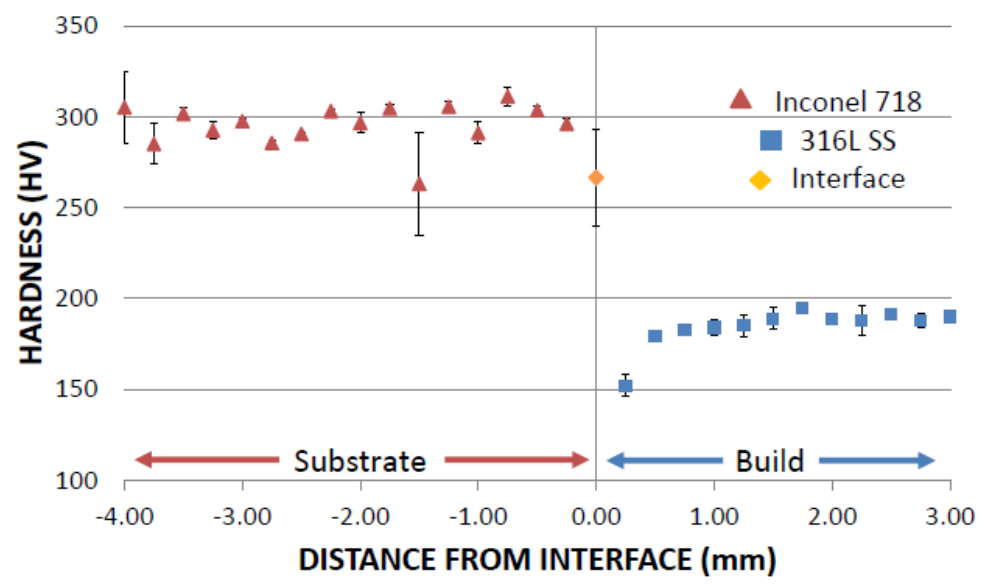

Figure 14 Microhardness across the fabricated 316L Stainless Steel on the Inconel 718 substrate

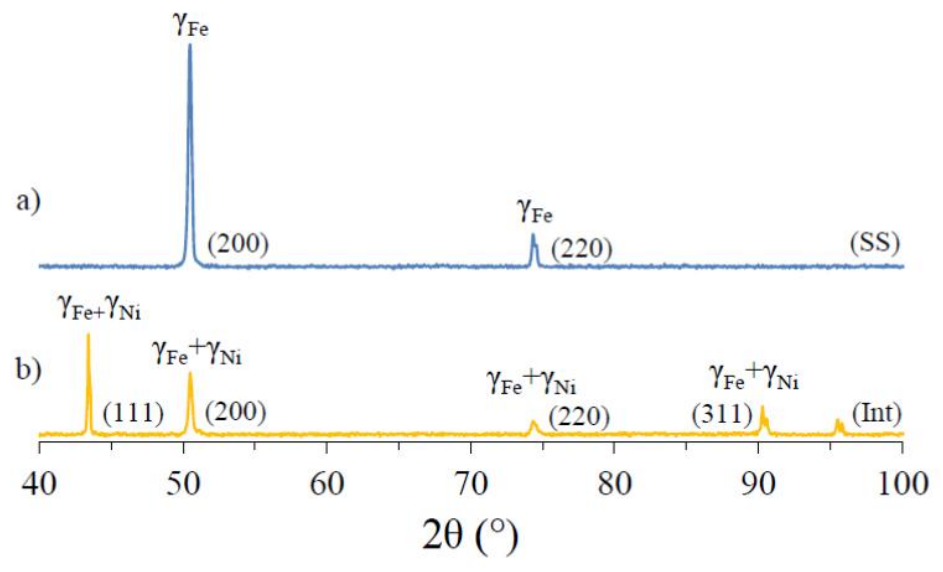

Figure 15 XRD spectra of the fabricated 316L SS onto the IN718 substrate at the interface. a) is spectra collected $10 \mathrm{~mm}$ interface in the fabricated $316 \mathrm{~L} \mathrm{SS}$. Spectra b) was collected at the interface of theIN718 substrate and fabricated 316L SS.

\section{Conclusions}

The fabrication of IN718/316L SS and 316L SS/IN718 was achieved via EBM AM technology. The presence of the welding features was substantially smaller than those provided via classic welding methods such as GTAW and comparable sizes to those of EBW. In addition to comparable feature size, the change in mechanical properties in the HAZ and the substrate were not greatly affected. The abundance of $\mathrm{NbC}$ and the sparse amount of low melting point 
phases (Laves) shows that the thermal process for joining at these interfaces are favorable to the mixing that occurs with these two alloys. The regions in which the formation of these precipitates are observed are small in comparison to conventional methods of joining. However, regions like the FZ or PMZ that experienced a high amount of carbide and precipitate formation can experience a reduction in corrosion resistance and embrittlement. Due to the depletion of the $\mathrm{Mo}$ and $\mathrm{Nb}$ in the austenitic solid solution the regions can experience a distinct drop in pitting resistance and overall corrosion resistance. The cracking in the 316L SS/IN718 is assumed to be caused by the deformation constraint imposed by the IN718 substrate, thus a solutionized substrate is suggested for further studies. Nonetheless, EBM was shown to be a good source for part production of mutli-material parts with improved joint qualities when compared to traditional welding processes. Further testing of the multi-material components in a nuclear quality environment is needed to truly evaluate the joint quality for use in nuclear reactors. In addition to multi-material components, the procedures used in this study can be used for repair applications where a material of dissimilar composition is grown onto a damaged component used as a substrate material.

Further work can be done to improve material joining characteristics. The optimization of parameters can help avoid the cracking that occurs within the 316L SS/IN718 and to reduce the amount of minor phases that form at the interface. In addition, the use of substrates with different microscostructural characteristics such as single crystal can be used to modify the additively deposited material. A more extensive characterization of the interface would be needed in order to have a better understanding of microstructural features at the interface. In addition, the evaluation of the mechanical and corrosive properties of these fabricated materials would need to be analyzed extensively before the material can be utilized in service.

\section{Acknowledgements}

The research presented here was performed at The University of Texas at El Paso (UTEP) within the W.M. Keck Center for 3D Innovation. The authors are grateful to Dr. Sara Gaytan, Christina Pickett, and Diego Mejorado for their assistance on various aspects of the project. Support was provided by RadiaBeam Systems through a grant from the Department of Energy (SBIR DE-SC0011826). 


\section{References}

[1] C. A. Terrazas, S. M. Gaytan, E. Rodriguez, D. Espalin, L. E. Murr, F. Medina and R. B. Wicker, "Multimaterial metallic structure fabrication using electron beam melting," Int. J., Adv. Manuf. Technol., 2013.

[2] S. J. Zinkle and G. S. Was, "Materials challenges in nuclear energy," Acta Materialia 61, pp. 735-758, 2013.

[3] C. A. Della Rovere, C. R. Ribeiro, R. Silva, N. G. Alcantara and S. E. Kuri, "Local mechanical properties of radial friction welded supermartensitic stainless steel pipes," Materials and Design, pp. 423-427, 2014.

[4] C. Jang, J. Lee, J. S. Kim and T. E. Jin, "Mechanical property variation within Inconel 82/182 dissimilar metal weld between low alloy steel and 316 stainless steel," International Journal of Pressure Vessels and Piping 85, pp. 635-646, 2008.

[5] R. G. Thompson and S. Genculu, "Microstructural Evolution in the HAZ of Inconel 718 and Correlation with the Hot Ductility Test," Welding Research Supplement, pp. 337-s - 345-s, 1983.

[6] G. A. Knorovsky, M. J. Cieslak, T. J. Headley, A. D. Romig and W. F. Hammetter, "Inconel 718: A solidification diagram," Metallurgical Transactions A, pp. 2149-2158, 1989.

[7] B. Weiss and R. Stickler, "Phase Instabilities During High Temperature Exposure of 316 Austenitic Stainless Steel," Metallurgical Transactions, pp. 851-866, 1972.

[8] M. F. Montemor, M. G. S. Ferreira, N. E. Hakiki and M. Da Cunha Belo, "Chemical composition and electronic structure of the oxide films formed on 316L stainless steel and nickel based alloys in high temperature aqueous environments," Corrosion Science, pp. 1635-1650, 2000.

[9] H. Naffakh, M. Shammanian and F. Ashrafizadeh, "Dissimilar welding of AISI 310 austenitic stainless steel to Nickel-based alloy Inconel 657," Journal of Materials Processing Technology, pp. 3628-3639, 2009.

[10] X. W. Wu, R. S. Chandel, H. P. Seow and H. Li, "Wide gap brazing of stainless steel to nickel-based superalloy," Journal of Materials Processing Technology 113, pp. 215-221, 2001.

[11] R. P. Mudge and N. R. Wald, "Laser Engineered Net Shaping Advances Additive Mnufacturing and Repair," Welding Journal, pp. 44-48, 2007.

[12] D. Hu and R. Kovacevic, "Sensing, modeling and control for laser-based additive manufacturing," Int. Journal of Machine Tools \& Manufacture 43, pp. 51-60, 2003.

[13] R. Hague, I. Campbell and P. Dickens, "Implications on design of rapid manufacturing," Proceedings of the Institution of Mechanical Engineers, Part C: Journal of Mechanical Engineering Science, pp. 25-30, 2003.

[14] J. Y. Hascoet, P. Muller and P. Mognol, "Manufacturing of complex parts with continuous functionally graded materials (FGM)," in Solid Freeform Fabrication Symposium, Austin, 2011.

[15] R. ACHARYA, R. BANSAL, J. J. GAMBONE and S. DAS, "A Coupled Thermal, Fluid Flow, and Solidification Modelfor the Processing of Single-Crystal Alloy CMSX-4 Through Scanning Laser Epitaxy for Turbine Engine Hot-SectionComponent Repair (Part I)," METALLURGICAL AND MATERIALS TRANSACTIONS B, vol. 45B, pp. 2247-2261, December 2014.

[16] R. R. Dehoff, M. M. Kirka, W. J. Sames, H. Bilheux, A. S. Tremsin, L. E. Lowe and S. S. Babu, "Site Specific Control of crystallographic grain orientation through electron beam additive manufacturing," Materials Science and Technology, vol. 31, no. 8, pp. 931-937, 2015.

[17] MatWeb , "Special Metals INCONEL (R) Alloy 718," 2014. [Online]. Available: http://www.matweb.com/search/DataSheet.aspx?MatGUID=94950a2d209040a09b89952d45086134\&ckck=1.

[18] MatWeb a, "AK Steel 316L Austenitic Stainless Steel," 2014. [Online]. Available: http://www.matweb.com/search/DataSheet.aspx?MatGUID=9e9ab696974044cab4a7fd83687934eb.

[19] L. E. Murr, E. Martinez, K. N. Amato, S. M. Gaytan, J. Hernandez, D. A. Ramirez, P. W. Shindo, F. Medina and R. B. Wicker, "Fabrication of Metal and Alloy Components by Additive Manufacturing: Examples of 3D Materials Science," Journal of Materials Research and Technology, vol. 1, no. 1, pp. 42-54, April-June 2012.

[20] F. Medina, "Reducing metal alloy powder costs for use in powder bed fusion additive manufacturing: 
Improving the economics for production," ProQuest Dissertations Publishing, El Paso, Texas, 2013.

[21] L. Achelis and V. Uhlenwinkel, "Characterisation of metal powders generated by a pressure-gas atomiser," Materials Science and Engineering: A, vol. 477, no. 1-2, pp. 15-20, 2008.

[22] W. Sames, "The OAKTrust Digital Repository," 0105 2015. [Online]. Available: http://oaktrust.library.tamu.edu/handle/1969.1/155230. [Accessed 812 2015].

[23] A. Strondl, M. Palm, J. Gnauk and G. Frommeyer, "Microstructure and mechanicalproperties of Nickel based superalloy IN718 produced by Rapid prototyping with electron beam melting (EHBM)," Materials Science and Technology, vol. 27, no. 5, pp. 876-883, May 2009.

[24] M. C. Fleming, Solidification Processing, McGraw-Hill, Inc, 1974.

[25] J. Benjamin, D. Katherasan, P. Sathiya and C. V. Srinivasa Murthy, "Weld metal characterization of 316L(N) austenitic stainless steel by electron beam welding process," Inmternational Journal of Engineering, Science and Technology, vol. 4, no. 2, pp. 169-176, 2012.

[26] J. N. Dupont, S. W. Banovic and A. R. Marders, "Microstructural Evolution and Weldabilityof Dissimilar Welds between a Super Austenitic Stainless Steel and Nickel-Based Alloys," The Welding Journal, pp. 125$135,2003$.

[27] M. Sireesha, S. K. Albert, V. Shankar and S. Sundaresan, "A comparative evaluation of welding consumables for dissimilar welds between 316LN austenitic stainless and Alloy 800," Journal of Nuclear Materials 279, pp. 65-76, 2000.

[28] J. D. Dupont, J. C. Lipold and S. D. Kiser, Welding Metallurgy and Weldability of Nickel-Base Alloys, Hoboken, New Jersey: Wiley, 2009.

[29] P. J. DiConza, R. R. Biederman and R. P. Singh, "Homogenization and thermomechanical processing of cast alloy 718," in The Minerals, Metals, and Materials Society, 1991.

[30] S. S. Al-Bermani, M. L. Blackmore, W. Zhang and I. Todd, "The Origin of Microstructural Diversity, Texture, and Mechanical Properties in Electron Beam Melted Ti-6Al-4V," METALLURGICAL AND MATERIALS TRANSACTIONS A, vol. 41 A, pp. 3422-3434, December 2010.

[31] J. C. Lippold and D. J. Kotecki, Welding Metallurgy and Weldability of Stainless Steels, Hoboken, New Jersey: John Wiley \&Sons, 2005.

[32] P. Prabhakar, W. J. Sames, R. DeHoff and S. S. Babu, "Computational modeling of residual stress formation during the electron beam melting process for Inconel 718," Additive Manufacturing, vol. 7, pp. 82-91, 2015.

[33] V. SHankar, T. P. S. Gill, S. L. Mannan and S. Sundaresan, Solidification cracking in austenitic stainless steel welds, vol. 28, Sadhana, 2003, pp. 359-382.

[34] E. L. Pryadko, H. Reuther, N. Shevchenko, A. B. Markov and A. Kolitsch, "Phase Composition of 316L Stainless Steel after Electron-Beam Irradiation Followed by Chromium Ion Implantation," in Proc. of the 10th Int. Conf. on Modification of Materials with Particle Beams and Plasma Flows, Tomsk, 2010. 


\section{List of Table Captions}

Table 1. Chemical composition of Powders

\section{List of Figure Captions}

Figure 1 Micrographs of the IN718 (a) and 316L SS (b) as-received precursor powder

Figure 2 Micrographs of as-received substrate microstructures utilyzed for fabrication. Hot rolled 316L SS with equiaxed grains shown in (a). Hot rolled IN718 shown in (b)

Figure 3 XRD Spectra for theIN718 and 316L SS substrates. Spectra shows texturing with respect to the (111) plane.

Figure 4 Microstructures of EBM-fabricated IN718. Micrograpgh (a) shows columnar nature of the grain structures. Micrograph (b) is a higher magnification image of themagnification of the grain structure. Micrographs of the joint interface for fabrcated IN718 onto 316L SS substrate joint interface are shown by (c) and (d). The arrow indicats the build direction.

Figure 5 Micrograph (a) is an inverse pole figure(IPF) color map of the of the fabricated IN718 on 316L SS substrates with pole figures and inverse pole figures in (b) and (c) respectively. Fabrication shows large columnar grains and strong texturing in the [001] direction. Micrograph (d) is an IPF color map of the joint interface between the IN718 and 316L SS substrate. Markers in a) and d) are each $500 \mu \mathrm{m}$.

Figure 6 Micrographic reconstruction of the 316L SS substrate revealing the HAZ. The marker in the micrograph is $500 \mu \mathrm{m}$.

Figure 7 EDS elemental concentration map of fabrication interface for IN718 on 316L SS. Center micrograph shows the SEM image of scanned area, marker is $50 \mu \mathrm{m}$. Arrow represents build direction.

Figure 8 Microhardness across the interface of the fabricated IN718 on 316L SS.

Figure 9 XRD spectra of fabricated IN718 on the 316L SS substrate. a) is spectra collected $10 \mathrm{~mm}$ from the interface in the fabricated IN718. Spectra $\mathrm{b}$ ) was collected at the joint interface of the 316L SS substrate and the fabricated IN718.

Figure 10 Micrographs of the fabricated 316L SS. Micrograph (a) and (b) shows defects of parmelted and un-melted layers with entrapped powder. Microstructures of the fabricated 316L Stainless Steel on the IN718 substrate. Brackets on the upper and lower part of the micrographs define the FZ and UZ. Arrow shows build direction.

Figure 11 EBSD of the fabricated 316L SS on IN718 and of the interface. The inverse pole figure (IPF) color map (a) shows preferred texture in the $\langle 001\rangle$ direction. The pole figure (b) and IPF distribution (c) show the dispersion of orientation of the FM. A Euler color map of the interface at higher magnification is shown in $\mathrm{d}$. The FZ and UZ are delineated by dashed lines on the Euler color map 
Figure 12 Micrograph (a) shows a backscatter electron image of dispersed acicular $\delta$ phase. Micrographic reconstruction of IN718 substrate post-fabrication showing defined HAZ. The arrow indicates build direction.

Figure 13 EDS elemental concentration map of fabrication interface for 316L SS on IN718 the shared UZ and FZ region. Marker. Arrow indicates build direction.

Figure 14 Microhardness across the fabricated 316L Stainless Steel on the Inconel 718 substrate

Figure 15 XRD spectra of the fabricated 316L SS onto the IN718 substrate at the interface. a) is spectra collected $10 \mathrm{~mm}$ interface in the fabricated 316L SS. Spectra b) was collected at the interface of theIN718 substrate and fabricated 316L SS. 